\title{
Annual Report on the External Quality Assessment of Therapeutic Drug Monitoring and Testing for Drugs of Abuse in Korea (2013)
}

Tae-Dong Jeong ${ }^{1}$, Gum-Gyoung $\mathrm{Gu}^{1}$, Sail Chun ${ }^{1}$, and Jeong-Ho $\mathrm{Kim}^{2}$, as Therapeutic Drug Monitoring Subcommittee, The Korean Association of Quality Assurance for Clinical Laboratory ${ }^{1}$ Department of Laboratory Medicine, Asan Medical Center, University of Ulsan College of Medicine; ${ }^{2}$ Department of Laboratory Medicine, Severance Hospital, Yonsei University College of Medicine, Seoul, Korea

Corresponding author: Sail Chun

Department of Laboratory Medicine, Asan Medical Center, University of Ulsan College of Medicine, 88 Olympic-ro 43-gil, Songpa-gu, Seoul 138-736, Korea Tel: $+82-2-3010-4513$

Fax: +82-2-478-0884

E-mail: sailchun@amc.seoul.kr
We performed two trials on the external quality assessment for therapeutic drug monitoring (TDM) and testing for drugs of abuse (DOA) organized by the Therapeutic Drug Monitoring (TDM) subcommittee of the Korean Association of Quality Assurance for Clinical Laboratories (KAQACL) in 2013. In each trial, two levels of control material for TDM, and positive and negative control material for DOA testing, were requested from candidate institutions. The number of participating laboratories was 106 and 105 for the first and second trials, respectively. The average number of drug items was 5.6 per institution. The most commonly tested substances were valproic acid, followed by digoxin, phenytoin, carbamazepine, and tacrolimus, in descending order. The mean inter-laboratory coefficients of variation for low- and high-level control materials were $9.3 \%$ and $6.7 \%$, respectively. The most widely used TDM analysers were Architect i System (Abbott Diagnostics, USA), followed by Cobas Integra (Roche Diagnostics, Switzerland) and Cobas c501 analyser (Roche Diagnostics). The number of participating laboratories for DOA testing increased by $30 \%$ compared with that in 2012 . We received $100 \%$ and $98.2 \%$ correct answers from the participating DOA laboratories in each trial, respectively. In the external quality assessment for TDM by the TDM subcommittee of KAQACL in 2013, the overall performance of TDM was similar to previous years and the inter-laboratory precision was improved compared with that in 2012. Continuous quality improvement for TDM testing is needed through participation in a proficiency-testing program.

(J Lab Med Qual Assur 2014;36:12-22)

Key Words : Quality assurance, Laboratory proficiency testing, Drug monitoring
서론

대한임상검사정도관리협회 약물검사분과위원회는 1995년 부터 혈중 치료적약물농도(therapeutic drug monitoring)검 사에 대한 신빙도조사를 시작하였고, 2007년부터는 남용약물 (drug of abuse)검사에 대한 신빙도조사를 실시하고 있다[14]. 저자들은 2013년 실시되었던 치료적약물농도검사 및 남용
약물검사의 신빙도조사결과를 분석하여 보고하고자 한다.

\section{재료 및 방법}

\section{1. 정도관리물질 및 대상기관}

총 2 회에 걸쳐 치료적약물농도검사 및 남용약물검사 신빙 도조사를 실시하였다. 제 1 회차 신빙도조사대상 정도관리물질 
Journal of LABORATORY MEDICINE and QUALITY ASSURANCE

Tae-Dong Jeong et al EQA Report for TDM and Drug of Abuse Testing (2013)

은 2013년 6월 3일 발송하였다. Lyphocheck TDM Control (Bio-Rad Laboratories, Hercules, CA, USA) level 1 (1301) 및 level 3 (13-02) 두 종류의 물질을 총 107 개 참여기관 에 발송하였고 Lyphocheck whole blood (WB) control (BioRad Laboratories) level 1 (13-01 WB) 및 level 3 (13-02 WB) 두 종류 물질은 cyclosporine, tacrolimus, sirolimus 검사를 시행하는 총 63 개 기관을 대상으로 발송하였다. 그리 고 Liquicheck Qualitative Urine Toxicology Control (BioRad Laboratories) negative (13-01 urine) 및 positive (1302 urine) 두 종류 물질을 30 개 기관에 발송하였다. 제 2 회차 정도관리물질 발송은 2013년 9월 24일에 시행하였다. Drug Control (Randox Laboratories, Northern Ireland, UK) level 1 (13-03) 및 level 2 (13-04) 두 종류의 물질을 총 107개 참여기관을 대상으로 발송하였고 Lyphocheck whole blood control (Bio-Rad Laboratories) level 1 (13-03 WB) 및 level 2 (13-04 WB) 두 종류의 물질을 cyclosporine, tacrolimus, sirolimus검사를 시행하는 총 63 개 기관을 대상으로 발송하였 다. 그리고 Liquicheck Qualitative Urine Toxicology Control (Bio-Rad Laboratories) negative (13-03 urine) 및 positive (13-04 urine) 두 종류의 물질을 30개 기관에 발송하였다.

\section{2. 신빙도조사 약물종목}

2013년도 대한임상검사정도관리협회 약물검사분과에 서 실시한 치료적약물농도검사 신빙도조사 약물종목은 acetaminophen, amikacin, amitriptyline, carbamazepine, digoxin, free phenytoin, free valproic acid, gentamicin, lithium, methotrexate, phenobarbital, phenytoin, salicylate, theophylline, tobramycin, valproic acid, vancomycin, cyclosporine, tacrolimus (FK-506), sirolimus 등 총 20항목 으로 제 1 회와 제 2 회차 모두 동일한 약물을 대상으로 하였다. 남용약물검사 신빙도조사종목은 3,4-methylenedioxymetha mphetamine, 9-COOH-11-nor- $\triangle 9-\mathrm{THC}$, benzoylecgonine, d-amphetamine, d-methamphetamine, ethanol, lysergic acid diethylamide, methadone, methaqualone, free morphine, nordiazepam, nortriptyline, oxazepam, phencyclidine, propoxyphene, secobarbital 등 16항목으로 제 1 회와 제 2 회차 모두 동일한 약물을 대상으로 하였다.

\section{3. 정도관리물질 제조방법}

정도관리물질 제조는 제조사의 지침대로 시행하도록 하 였다. 1회차에 발송된 치료적약물농도검사 정도관리물질 Lyphocheck TDM control (Bio-Rad Laboratories)은 검사
당일 Class-A 용적피펫(volumetric pipet)을 사용하여 탈이온 수 $5.0 \mathrm{~mL}$ 를 넣어 용해시켜 실온에 15 분간 세워 둔 후 검사 전 혼합하여 사용하도록 하였다. 2회차에 발송된 Drug Control (Randox Laboratories)은 검사 당일 Class-A 용적피펫을 사 용하여 탈이온수 $5.0 \mathrm{~mL}$ 를 넣어 용해시켜 실온에 30분간 세 워 둔 후 검사 전 혼합하여 사용하도록 하였다. Lyphocheck whole blood control (Bio-Rad Laboratories)은 검사 당일 Class-A 용적피펫을 사용하여 탈이온수 $2.0 \mathrm{~mL}$ 를 넣어 용해 시켜 실온에 20 분간 세워 둔 후 검사 전 혼합하여 사용하도록 하였다. 남용약물검사물질은 액상으로 전처리 없이 검사하도 록 하였다.

\section{4. 수탁기관 인정기준}

본 분과위원회에서 정한 치료약물농도검사의 수탁기관 인 정기준은 다음과 같았다. 첫째, 특정 회차에서 약물종목 중 'unacceptable'인 약물종목이 2건 이하이어야 한다. 단 장비 별 peer group이 5 기관 이하일 경우 'unacceptable'인 약물종 목이 3건 이하이어야 한다. 둘째, 참여한 약물종목 중 해당 약 물종목이 2회 연속으로 모든 정도관리물질결과(연속된 4개 검 사)가 'unacceptable'인 종목이 없어야 한다. 단 장비별 peer group이 5 기관 이하일 경우 해당 약물종목이 3회 연속으로 모든 정도관리물질결과(연속된 6개 검사)가 'unacceptable' 인 종목이 없어야 한다. 'Unacceptable'의 기준은 약물검사 분과 'acceptable' 판정 허용범위기준을 벗어난 경우를 말한 다. 약물종목별 허용기준은 다음과 같다. Acetaminophen, amikacin, amitriptyline, carbamazepine, cyclosporine, free phenytoin, free valproic acid, methotrexate, salicylate, sirolimus, tacrolimus (FK-506), vancomycin 등의 허용기 준은 $\pm 3 \mathrm{SD}$ 또는 $\pm 10 \%$ 이고, gentamicin, phenobarbital, phenytoin, theophylline, tobramycin, valproic acid 등의 약 물 허용기준은 $\pm 25 \%$ 이다. Digoxin은 $\pm 20 \%$ 또는 $0.2 \mathrm{ng} /$ $\mathrm{mL}$ 이고 lithium은 $\pm 20 \%$ 또는 $0.3 \mathrm{mmol} / \mathrm{L}$ 이다.

\section{5. 결과분석 및 통계}

약물농도의 보고단위 및 소수점 유효숫자를 약물검사분과위 원회에서 제시한 것으로 하지 않고 임의대로 한 기관에 대해서 는 본 위원회 제시 안을 참고하여 일괄 환산 처리하였다. 또한 검사장비코드를 기록하지 않은 기관은 2012년과 동일 코드로 처리하였으며 통계분석은 각 검사종목별로 장비의 차이를 고 려하지 않은 전체 통계와 각 장비별(peer group)로 평균, 표준 편차, 표준편차지수(standard deviation index) 값을 내되, 표 준편차지수 값이 +3.0 또는 -3.0 을 벗어나는 기관의 결과 값 
은 제외하고 다시 평균, 표준편차, 및 표준편차지수 값을 계산 하였다. 단, 참여기관이 단일기관인 경우 통계에서 제외하였 다. 또한 각 군별로 변이계수(coefficient of variation), 최젓값 및 최댓값을 산출하였다. 결과분석 및 통계처리는 Microsoft Excel 2010 (Microsoft, Redmond, WA, USA) 프로그램과 Microsoft Access 2010 (Microsoft) 프로그램을 사용하였다.

\section{결과}

\section{1. 신빙도조사 참여기관 및 검사종목}

1 회차는 107 기관 중 106 기관이 회신하여 회신율 $99.1 \%, 2$ 회차는 107 기관 중 105 기관이 회신을 하여 회신율 $98.1 \%$ 였 다. 기관당 평균 검사종목 수는 5.6종목이었다. 가장 많은 기
관에서 회신한 약물농도검사종목은 valproic acid $86.4 \%$, digoxin $70.6 \%$, phenytoin $55.1 \%$, carbamazepine $50.9 \%$ 등 4종목으로서 $50.0 \%$ 이상의 기관에서 응답하였다. 다음으로 tacrolimus $49.5 \%$, vancomycin $48.1 \%$, theophylline $47.7 \%$, cyclosporine $43.9 \%$ 순이었고, $10 \%$ 미만의 회신을 보인 종 목은 sirolimus, amikacin, acetaminophen, gentamicin, salicylate, tobramycin, free phenytoin, free valproic acid 등 의 종목이었다. Amitriptyline과 pirimidon 두 약물의 응답률 은 1회차, 2 회차 모두 $0 \%$ 였다(Table 1).

\section{2. 검사장비 이용현황}

치료약물농도감시 검사장비는 Architect i System (Abbott Diagnostics, Abbott Park, IL, USA)의 사용률이 $37.4 \%$ 로 가

Table 1. Response rate of the 2013 therapeutic drug monitoring proficiency testing by the Korean Association of Quality Assurance for Clinical Laboratories, including the previous three years

\begin{tabular}{|c|c|c|c|c|c|c|c|c|c|c|}
\hline \multirow{3}{*}{ Test substances } & \multicolumn{8}{|c|}{ Year } & \multirow{2}{*}{\multicolumn{2}{|c|}{ Response rate }} \\
\hline & \multicolumn{2}{|c|}{2010} & \multicolumn{2}{|c|}{2011} & \multicolumn{2}{|c|}{2012} & \multicolumn{2}{|c|}{2013} & & \\
\hline & 1 st & 2nd & 1 st & 2nd & $1 \mathrm{st}$ & 2nd & 1st & 2nd & 2013 & 2010-2012 \\
\hline Acetaminophen & 7 & 7 & 7 & 7 & 7 & 7 & 7 & 6 & 6.1 & 6.5 \\
\hline Amikacin & 12 & 12 & 10 & 10 & 9 & 8 & 8 & 7 & 7.0 & 9.4 \\
\hline Amitriptyline & 0 & 0 & 0 & 0 & 0 & 0 & 0 & 0 & 0.0 & 0.0 \\
\hline Carbamazepine & 67 & 65 & 60 & 59 & 58 & 55 & 55 & 54 & 50.9 & 56.0 \\
\hline Cyclosporine & 45 & 46 & 46 & 47 & 46 & 47 & 47 & 47 & 43.9 & 42.6 \\
\hline Digoxin & 83 & 83 & 80 & 80 & 78 & 77 & 76 & 75 & 70.6 & 74.0 \\
\hline Ethosuximide & 1 & 1 & 0 & 0 & 0 & 0 & 0 & 0 & 0.0 & 0.3 \\
\hline Free phenytoin & 3 & 4 & 3 & 2 & 2 & 2 & 2 & 2 & 1.9 & 2.5 \\
\hline Free valproic acid & 1 & 2 & 1 & 1 & 1 & 1 & 2 & 1 & 1.4 & 1.1 \\
\hline Gentamicin & 8 & 7 & 7 & 7 & 7 & 7 & 6 & 5 & 5.1 & 6.6 \\
\hline Lithium & 31 & 31 & 32 & 31 & 33 & 32 & 33 & 33 & 30.8 & 29.2 \\
\hline Methotrexate & 18 & 17 & 17 & 17 & 17 & 17 & 18 & 18 & 16.8 & 15.8 \\
\hline Phenobarbital & 49 & 48 & 46 & 46 & 45 & 43 & 43 & 41 & 39.3 & 42.6 \\
\hline Phenytoin & 68 & 65 & 63 & 63 & 62 & 60 & 59 & 59 & 55.1 & 58.6 \\
\hline Primidone & 1 & 1 & 0 & 0 & 0 & 0 & 0 & 0 & 0.0 & 0.3 \\
\hline Salicylate & 5 & 5 & 5 & 5 & 6 & 6 & 5 & 5 & 4.7 & 4.9 \\
\hline Sirolimus & - & - & 8 & 8 & 9 & 9 & 9 & 9 & 8.4 & 7.8 \\
\hline Tacrolimus & 45 & 47 & 46 & 46 & 51 & 53 & 53 & 53 & 49.5 & 44.3 \\
\hline Theophylline & 64 & 64 & 60 & 59 & 56 & 51 & 52 & 50 & 47.7 & 54.5 \\
\hline Tobramycin & 6 & 6 & 6 & 6 & 5 & 5 & 5 & 4 & 4.2 & 5.2 \\
\hline Valproic acid & 91 & 91 & 92 & 92 & 91 & 92 & 93 & 92 & 86.4 & 84.5 \\
\hline Vancomycin & 44 & 45 & 46 & 47 & 48 & 49 & 52 & 51 & 48.1 & 42.9 \\
\hline Total $\mathrm{N}$ of institutions & 110 & 110 & 108 & 108 & 107 & 107 & 106 & 105 & 26.3 & 26.8 \\
\hline
\end{tabular}

Values are presented as \%. 
Tae-Dong Jeong et al EQA Report for TDM and Drug of Abuse Testing (2013)

장 높았고, 그 다음으로 Cobas Integra (Roche Diagnostics, Basel, Switzerland), Cobas c501 (Roche Diagnostics) 순이 었다(Table 2). 리튬(lithium)검사의 경우 검사방법이나 장비 의 사용에 있어서 전체 리튬 검사기관의 $78.1 \%$ 인 25 기관에서 이온선택전극(ion selective electrode)법이 이용되고 있었고, 건식 슬라이드(dry slide)법을 사용하는 기관은 $15.6 \%$ 인 5 기 관, $6.3 \%$ 인 2 기관에서는 원자흡광광도계(atomic absorption spectrometer)법을 사용하였다.

\section{3. 치료적약물농도검사}

치료적약물농도검사의 검사실 간 평균 변이계수는 저농도 $9.3 \%$ 였고 고농도 $6.7 \%$ 였다(Table 3). 약물 종류별 신빙도조 사결과는 장비를 고려하지 않은 전체 참가기관의 평균, 표준편 차 및 변이계수와 장비를 고려한 평균, 표준편차 및 변이계수

Table 2. Distribution of the instruments used for therapeutic drug monitoring for the Korean Association of Quality Assurance for Clinical Laboratories proficiency testing during 2013

\begin{tabular}{|c|c|c|c|c|}
\hline \multirow{2}{*}{ Name of instrument } & \multicolumn{4}{|c|}{ Year } \\
\hline & 2010 & 2011 & 2012 & 2013 \\
\hline Abbott Architect i System & 14.5 & 21.1 & 33.2 & 37.4 \\
\hline Roche Cobas Integra & 16.9 & 17.6 & 19.5 & 19.9 \\
\hline Roche Cobas c501 (Cobas 6000) & 6.5 & 6.9 & 6.0 & 6.5 \\
\hline Roche/Hitachi Systems & 5.1 & 5.7 & 5.8 & 5.7 \\
\hline Abbott AxSym & 25.4 & 19.5 & 8.2 & 5.5 \\
\hline Siemens Diagnostics Advia Centaur & 2.0 & 1.8 & 2.6 & 3.9 \\
\hline Siemens Diagnostics Viva-E & 5.5 & 5.2 & 3.2 & 3.4 \\
\hline Siemens Diagnostics Dimension & 4.0 & 3.5 & 4.0 & 2.7 \\
\hline Beckman UniCel DxC Synchron & 2.3 & 2.4 & 2.4 & 2.3 \\
\hline Abbott TDx/TDxFLx & 7.0 & 3.3 & 2.3 & 2.3 \\
\hline Toshiba chemistry analyzer & 2.8 & 2.5 & 2.1 & 1.8 \\
\hline Waters LC/MS/MS & 0.5 & 1.6 & 1.1 & 1.2 \\
\hline AVL Scientific & - & 0.6 & 0.8 & 1.0 \\
\hline Beckman Synchron LX Systems & 1.8 & 1.7 & 1.8 & 0.9 \\
\hline Nova CRT/Nucleus & - & 0.9 & 0.8 & 0.9 \\
\hline Roche Cobas e601/E170 & 1.0 & 0.9 & 0.8 & 0.9 \\
\hline Abbott Architect c system/Aeroset & 1.8 & 0.6 & 0.5 & 0.7 \\
\hline Vitros 5,1 FS Chemistry System & 0.2 & 0.9 & 0.8 & 0.6 \\
\hline Agilent technologies & 0.2 & 0.0 & 0.5 & 0.5 \\
\hline Siemens Diagnostics Vista & - & - & 0.4 & 0.5 \\
\hline Radioimmunoassay & 0.3 & 0.0 & 0.3 & 0.3 \\
\hline Nova & - & 0.2 & 0.2 & 0.2 \\
\hline Siemens Diagnostics Advia Centaur CP & 0.1 & 0.1 & 0.2 & 0.2 \\
\hline Konelab & - & - & 0.3 & 0.2 \\
\hline Roche 9100 Series (ISE Mode) & - & 0.1 & 0.5 & 0.2 \\
\hline Varian (AAS) & - & 0.2 & 0.2 & 0.2 \\
\hline Vitros DT60 II Chemistry System & - & 0.2 & 0.2 & 0.1 \\
\hline BioMerieux VIDAS & 1.0 & 1.0 & 1.1 & 0.1 \\
\hline Other methods & 0.3 & 0.5 & 0.3 & 0.1 \\
\hline Total & 100.0 & 100.0 & 100.0 & 100.0 \\
\hline
\end{tabular}

Values are presented as $\%$. 
Journal of LABORATORY MEDICINE and QUALITY ASSURANCE

Tae-Dong Jeong et al • EQA Report for TDM and Drug of Abuse Testing (2013)

Table 3. Mean inter-laboratory CV for each substance using low- and high-level control materials during the last 5 years

\begin{tabular}{|c|c|c|c|c|c|c|c|c|c|c|c|c|}
\hline \multirow[b]{2}{*}{ Substance } & \multicolumn{6}{|c|}{ Inter-laboratory CV for low-level control materials } & \multicolumn{6}{|c|}{ Inter-laboratory CV for high-level control materials } \\
\hline & $\begin{array}{l}\mathrm{N} \text { of } \\
\text { labs }\end{array}$ & $\begin{array}{l}\text { Average } 2008 \\
\text { to } 2012\end{array}$ & $\begin{array}{l}2012 \\
\text { (1st) }\end{array}$ & $\begin{array}{l}2012 \\
\text { (2nd) }\end{array}$ & $\begin{array}{l}2013 \\
\text { (1st) }\end{array}$ & $\begin{array}{l}2013 \\
\text { (2nd) }\end{array}$ & $\begin{array}{l}N \text { of } \\
\text { labs }\end{array}$ & $\begin{array}{l}\text { Average } 2008 \\
\text { to } 2012\end{array}$ & $\begin{array}{l}2012 \\
\text { (1st) }\end{array}$ & $\begin{array}{l}2012 \\
\text { (2nd) }\end{array}$ & $\begin{array}{l}2013 \\
\text { (1st) }\end{array}$ & $\begin{array}{l}2013 \\
\text { (2nd) }\end{array}$ \\
\hline Amikacin & 8 & 8.0 & 10.2 & 4.8 & 5.2 & 13.0 & 8 & 6.8 & 5.1 & 8.1 & 6.3 & 5.4 \\
\hline Amitriptyline & - & - & - & - & - & - & - & - & - & - & - & - \\
\hline Cyclosporine & 47 & 11.4 & 11.1 & 13.6 & 11.9 & 10.5 & 47 & 9.5 & 10.1 & 10.4 & 9.9 & 9.5 \\
\hline Digoxin & 76 & 16.3 & 13.6 & 15.4 & 15.4 & 25.2 & 77 & 8.8 & 9.8 & 7.3 & 9.1 & 10.8 \\
\hline Free phenytoin & 2 & 11.7 & 10.1 & 0.8 & 9.5 & 4.9 & 2 & 20.7 & 24.2 & 15.5 & 12.9 & 7.1 \\
\hline Free valproic acid & 1 & - & - & - & - & - & 1 & 18.2 & - & - & & \\
\hline Gentamicin & 6 & 6.7 & 6.1 & 7.9 & 4.7 & 4.0 & 7 & 8.1 & 6.2 & 8.2 & 7.2 & 10.2 \\
\hline Phenobarbital & 43 & 6.8 & 6.7 & 6.3 & 6.9 & 7.2 & 43 & 7.4 & 6.7 & 6.9 & 6.7 & 5.5 \\
\hline Phenytoin & 59 & 6.1 & 5.4 & 5.0 & 7.2 & 5.4 & 60 & 5.0 & 4.6 & 4.6 & 7.5 & 6.4 \\
\hline Primidone & - & - & - & - & - & - & - & 7.0 & - & - & & \\
\hline Salicylate & 5 & 8.4 & 10.7 & 9.5 & 5.9 & 6.7 & 6 & 2.5 & 2.2 & 2.0 & 1.1 & 0.5 \\
\hline Sirolimus & 9 & 13.2 & 10.7 & 4.4 & 13.6 & 12.0 & 9 & 13.2 & 13.5 & 13.0 & 8.8 & 7.9 \\
\hline Tacrolimus & 53 & 18.3 & 9.2 & 19.1 & 9.1 & 7.4 & 53 & 9.3 & 9.1 & 7.8 & 7.3 & 7.3 \\
\hline Theophylline & 52 & 5.9 & 5.0 & 5.0 & 4.4 & 4.6 & 51 & 5.3 & 5.2 & 5.9 & 4.9 & 4.9 \\
\hline Tobramycin & 5 & 20.3 & 26.5 & 20.4 & 39.5 & 11.6 & 5 & 15.3 & 15.1 & 13.4 & 16.1 & 2.3 \\
\hline Valproic acid & 93 & 7.5 & 8.4 & 8.4 & 7.9 & 6.3 & 92 & 5.8 & 6.0 & 5.0 & 4.8 & 3.5 \\
\hline
\end{tabular}

Abbreviation: labs, laboratories.

Values are presented as \%.

를 구분하여 요약하였다(Tables 4-7). 2013년 시행된 치료적 약물농도검사 신빙도조사에 참여한 모든 기관은 수탁기관 인 정기준을 만족하였다.

\section{4. 남용약물검사}

남용약물검사 신빙성조사에 참여한 기관 수는 1 차 25 기 관, 2차 26기관이었다. 13-01 (urine), 13-02 (urine), 1303 (urine) 검체는 모든 기관에서 정답을 보고하였다. 1304 (urine) 검체는 d-methamphetamine 두 기관, free morphine과 lysergic acid diethylamide은 각각 1 개의 기관에 서 오답을 보고하였다(Table 8). 남용약물검사의 신빙도조사 결과 모든 기관이 수탁기관 인정기준을 만족하였다.

\section{고찰}

대한임상정도관리협회 약물검사분과위원회의 치료적약물 농도검사 신빙도조사사업 참여기관 수는 사업이 시작된 이 후 2007년까지 꾸준히 증가하다가 이후 유사한 수준을 보였 다. 2013 년 참가기관 수는 1 회차에 106 기관, 2 회차에 105 기 관으로 2012년에 107기관에 비해 1-2기관 감소하였다. 2013 년 평균 회신율은 $98.6 \%$ 로 2012 년 $100 \%$ 에 비해 $1.4 \%$ 감소 하였다. 기관당 평균 검사종목 수는 5.6종목으로 2008-2012 년 최근 5 개년간 평균 5.7 종목과 유사하였다. 최근 5 년간 가 장 많은 기관에서 회신한 약물종목은 valproic acid였다. 대체 적으로 각 기관에서 회신한 약물종목은 예년과 유사한 수준 이었다. Cyclosporine, vancomycin, tacrolimus 등 약물들의 응답률은 최근 3년(2010-2012) 간 평균 응답률에 비해 증가 


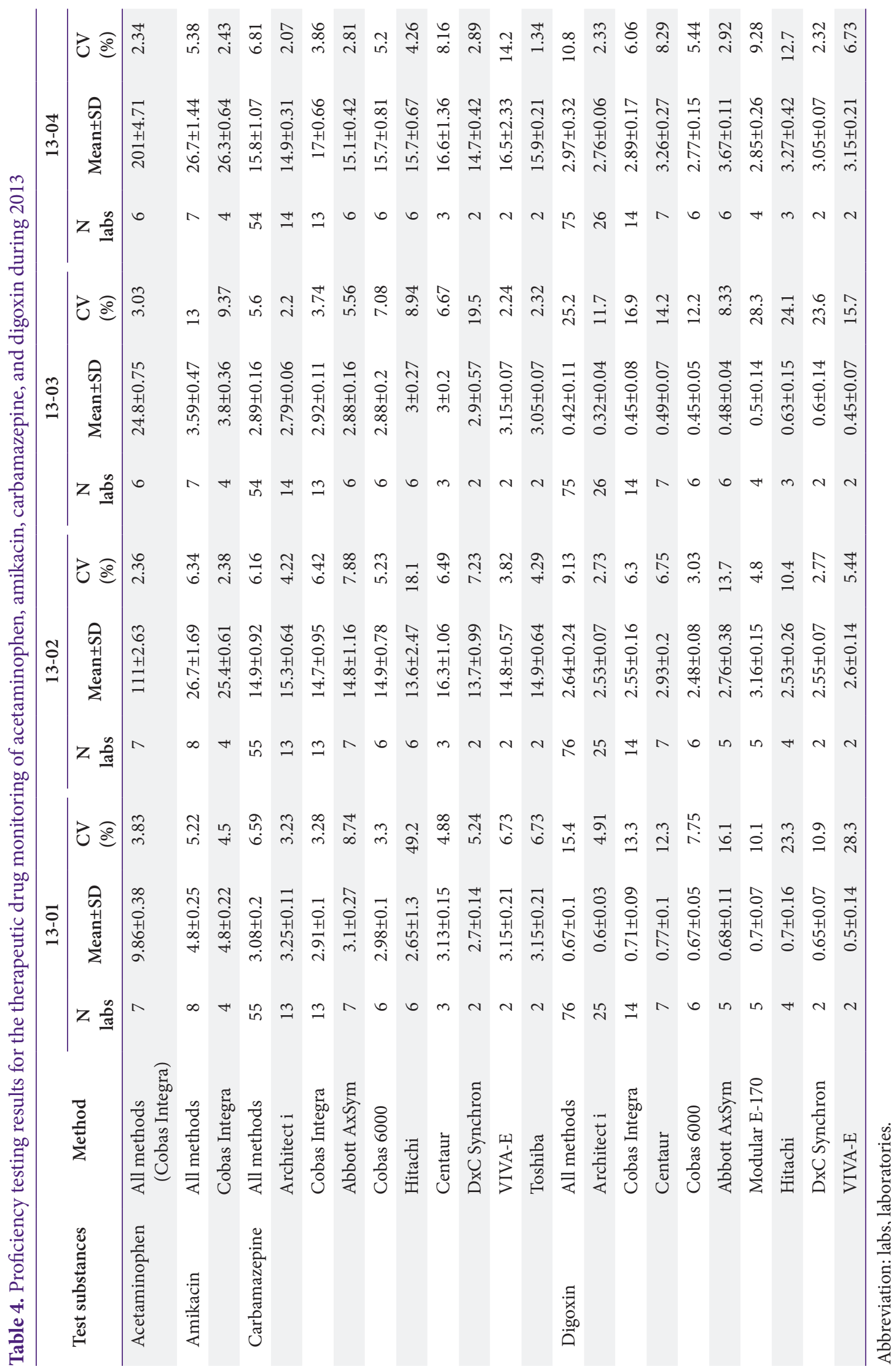




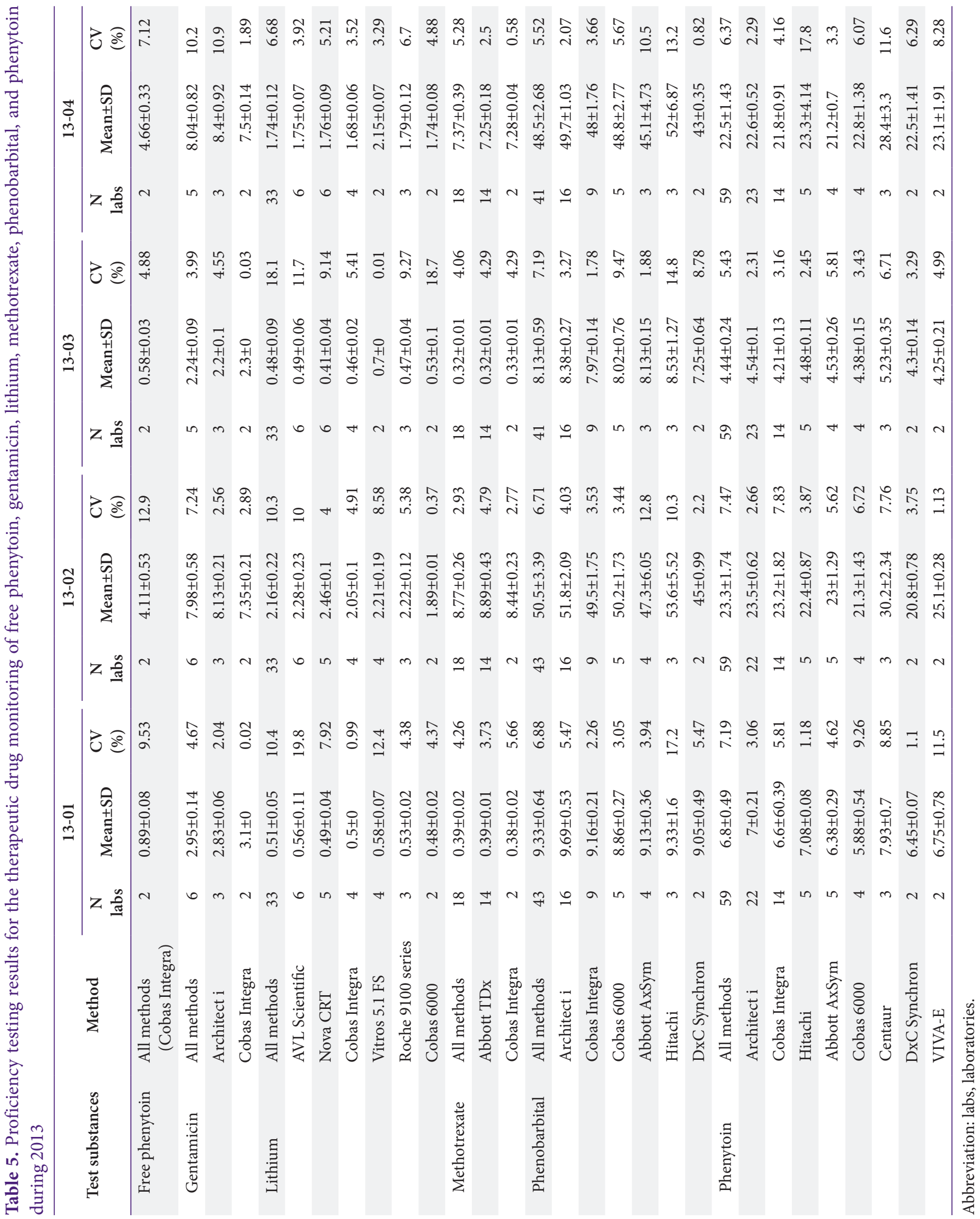




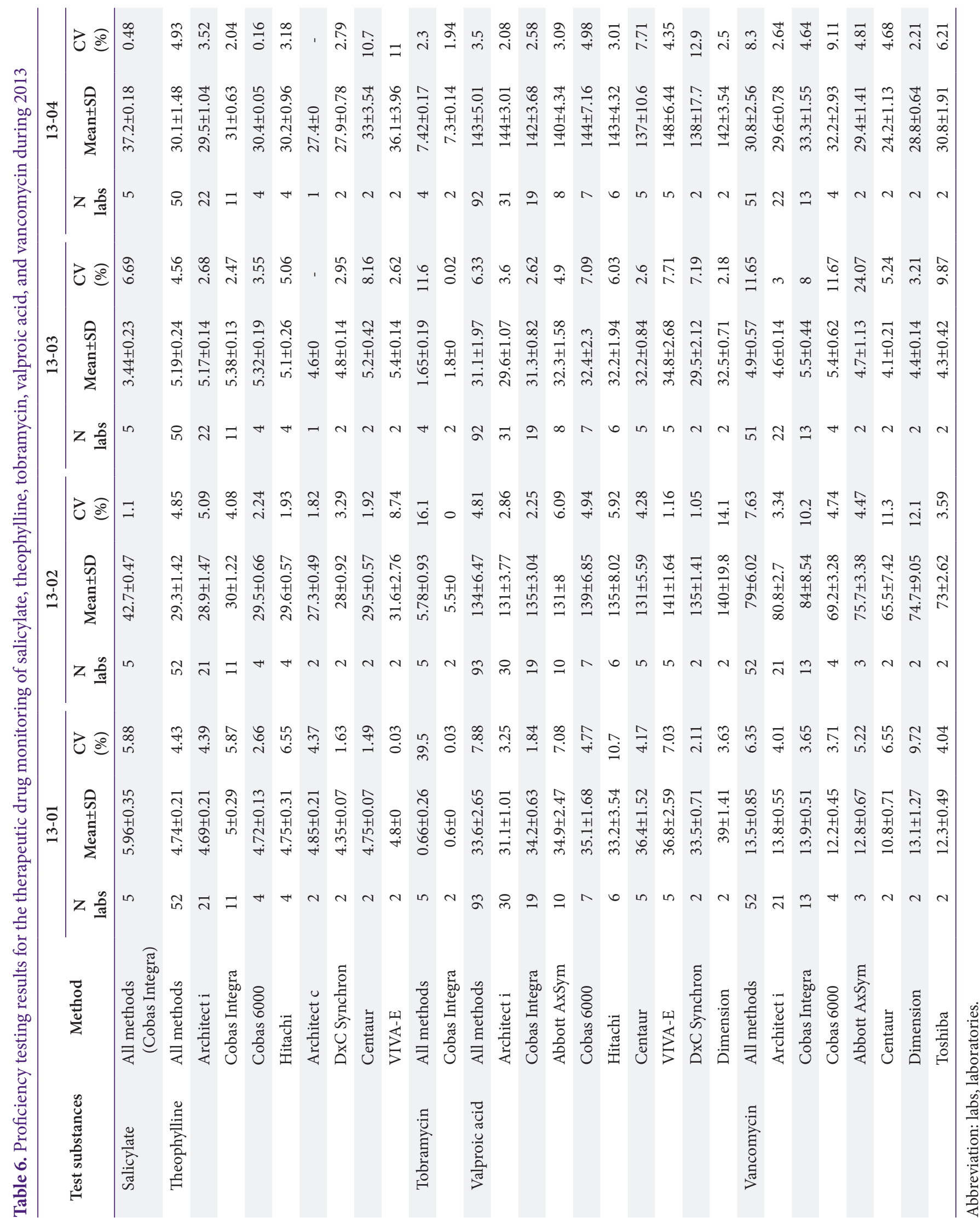




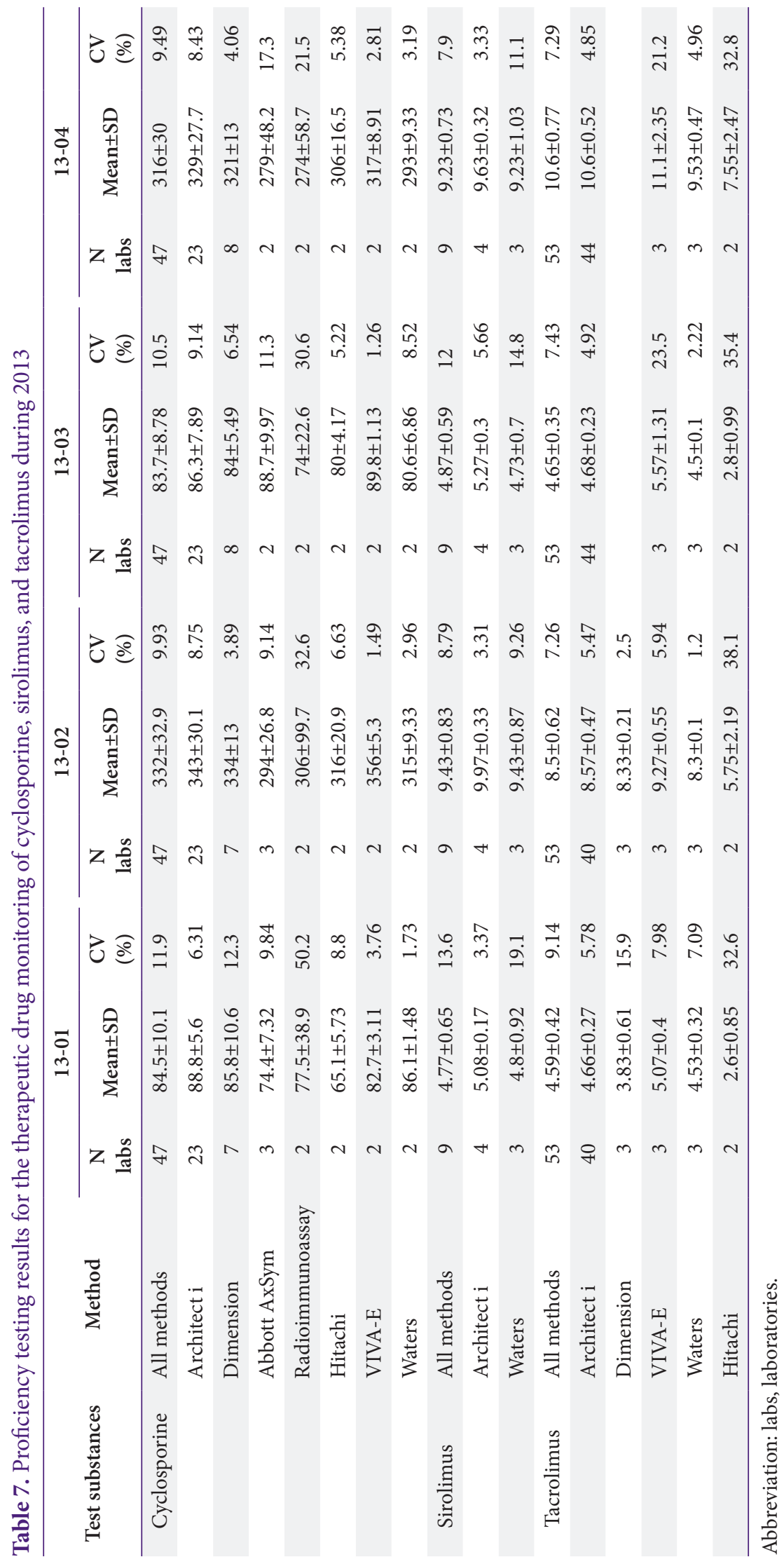


Journal of LABORATORY MEDICINE and QUALITY ASSURANCE

Tae-Dong Jeong et al • EQA Report for TDM and Drug of Abuse Testing (2013)

Table 8. Drugs of abuse and the number of participating laboratories showing the percentage of correct answers gained in the proficiency testing by the Korean Association of Quality Assurance for Clinical Laboratories during 2013

\begin{tabular}{lcccc}
\hline \multirow{2}{*}{ Test substances } & \multicolumn{4}{c}{ Participating laboratories during 2013 } \\
\cline { 2 - 4 } & 13-01 (urine) & 13-02 (urine) & 1303 (urine) & 13-04 (urine) \\
\hline d-Methamphetamine & $24(100)$ & $24(100)$ & $26(100)$ & $26(92)$ \\
d-Amphetamine & $14(100)$ & $14(100)$ & $15(100)$ & $15(100)$ \\
Morphine, Free & $19(100)$ & $19(100)$ & $20(100)$ & $20(95)$ \\
9-COOH-11-nor- $\Delta$ 9-THC & $17(100)$ & $17(100)$ & $18(100)$ & $18(100)$ \\
Benzoylecgonine & $18(100)$ & $18(100)$ & $19(100)$ & $19(100)$ \\
Phencyclidine & $9(100)$ & $9(100)$ & $9(100)$ & $9(100)$ \\
3,4-Methylenedioxymethamphetamine & $7(100)$ & $7(100)$ & $8(100)$ & $8(100)$ \\
Oxazepam & $3(100)$ & $3(100)$ & $4(100)$ & $4(100)$ \\
Secobarbital & $2(100)$ & $2(100)$ & $2(100)$ & $2(100)$ \\
Methadone & $3(100)$ & $3(100)$ & $4(100)$ & $4(100)$ \\
Nordiazepam & $2(100)$ & $2(100)$ & $3(100)$ & $3(100)$ \\
Ethanol & $2(100)$ & $2(100)$ & $2(100)$ & $2(100)$ \\
Nortriptyline & $2(100)$ & $2(100)$ & $2(100)$ & $2(100)$ \\
Lysergic acid diethylamide & $1(100)$ & $1(100)$ & $2(100)$ & $2(50)$ \\
Propoxyphene & $1(100)$ & $1(100)$ & $2(100)$ & $2(100)$ \\
Methaqualone & $1(100)$ & $1(100)$ & $1(100)$ & $1(100)$ \\
\hline
\end{tabular}

Values are presented as number (\% of correct answers).

된 반면 digoxin, phenytoin, carbamazepine, theophylline, phenobarbital 등의 약물들은 응답률이 감소하였다. 2013 년 전체 참여기관의 tacrolimus 약물에 대한 평균 응답률은 $49.5 \%$ 로 2010-2012년 평균 응답률 44.3\%에서 5.2\%가 상 승하여 증가 폭이 가장 컸다. 반면 응답률 감소폭이 가장 큰 약 물은 theophylline으로 2010-2012년 평균 응답률이 54.5\% 였지만 2013년 응답률은 $47.7 \%$ 로 $6.8 \%$ 감소하였다.

약물검사분과에서는 각 기관에 기관별 평가를 위해서 검사 장비 차이를 고려하지 않은 종목별 표준편차지수 값과 검사장 비별 표준편차지수 값을 별도로 계산하여 보고하였다. 2013 년 저농도와 고농도 정도관리물질의 검사실 간 평균 변이계 수는 각각 $9.3 \%, 6.7 \%$ 로 최근 5 개년의 평균 검사실 간 변이 계수인 저농도 $11.3 \%$, 고농도 $9.2 \%$ 에 비해 변이계수가 감 소하여 정밀도가 향상된 소견을 보였다. 약물별 검사실 간 변 이계수는 대체로 예년과 유사하였다. Cyclosporine의 경우 radioimmunoassay법을 사용하는 기관은 두 기관으로 평균 검사실 간 변이계수는 $33.7 \%$ 였다. 이는 cyclosporine검사에서 참여기관 수가 동일한 다른 장비를 사용하는 기관의 평균 변 이계수 $4.3 \%$ 보다 매우 높았다. 그리고 Hitachi 장비를 사용하 여 tacrolimus 약물농도검사를 시행하는 검사실의 검사실 간 변이계수는 평균 $34.7 \%$ 로, 장비를 고려하지 않은 전체 평균
$7.8 \%$ 보다 높았다. 비록 참여기관 수가 적다고 하더라도 동일 검사법을 사용하는 검사실 간 변이계수가 큰 종목들은 정밀도 의 재평가가 필요할 것으로 판단되었다.

2013년 남용약물검사 신빙도조사 참여기관 수는 1회차 25 기관, 2 회차 26 기관으로 2012 년 1회차 21 기관, 2 회차 18 기 관에 비해 약 $30 \%$ 증가하였다. 증가된 참여기관은 대부분 3 차의료기관의 검사실이었다. 남용약물검사 신빙도조사 정 답률은 예년과 유사하였지만 d-methamphetamine 2기관, free morphine과 lysergic acid diethylamide이 각각 1기관 에서 오답을 보고하였다. D-methamphetamine의 음성 정도 관리물질농도는 $50.0 \mathrm{ng} / \mathrm{mL}$ 미만이었고 양성 정도관리물질 농도는 $1,901 \mathrm{ng} / \mathrm{mL}$ 이었다. Free morphine과 lysergic acid diethylamide 약물 역시 양성 및 음성 정도관리물질농도 차이 가 매우 크므로 정성검사에서 오답을 보고한 기관은 결과보고 시 사무적 오차가 있었는지 여부와 남용약물검사의 cut-off를 점검할 필요가 있었다. 또한 남용약물검사 의뢰건수가 적은 기 관에서는 검사 kit의 유통기한을 확인한 후 남용약물검사를 실 시해야 할 것으로 생각되었다.

결론적으로 2013년 치료적약물농도검사 신빙도조사에서 참 여기관 수는 최근 5 년간 유사하였고, 저농도 및 고농도 정도관 리물질검사의 검사실 간 변이계수는 2010 - 2012년보다 감소하 
Tae-Dong Jeong et al EQA Report for TDM and Drug of Abuse Testing (2013)

여 전반적으로 약물검사의 정밀도가 향상된 소견을 보였다. 남 용약물검사 참여기관 수는 2012년에 비해 $30 \%$ 가량 증가하였 다. 치료적약물농도검사는 환자 개개인의 적정약물요법을 위해 필수적인 검사로 각 검사실에서는 지속적인 신빙도조사사업 참 여를 통하여 검사의 질을 높여나가야 할 것으로 생각되었다.

\section{약물검사분과 위원(2013)}

전사일(위원장, 울산의대), 구금경(간사, 서울아산병원), 권 계철(충남의대), 김병광(세브란스병원), 김승완(건국대학교병 원), 김정호(연세의대), 서순팔(전남의대), 송경은(경북의대), 송정한(서울의대), 윤여민(건국의대), 이수연(성균관의대), 이 용화(순천향의대), 정태동(울산의대), 홍수지(서울대학교병 원)

\section{REFERENCES}

1. Kim JQ, Jung YS, Kwon OH, Kwon HJ, Kim YK, Kim JW, et al. Annual report on 2008 external quality assessment in therapeutic drug monitoring in Korea (1995). J Clin Pathol Qual Control 2009;18:119-25.

2. Kim JH, Lee W, Kim BK, Lee SY, Chun S, Kwon GC, et al. Annual report on 2008 external quality assessment in therapeutic drug monitoring and drug of abuse in Korea (2008). J Lab Med Qual Assur 2009;31:125-41.

3. Kim JH, Kim BK, Lee W, Lee SY, Chun S, Kwon GC, et al. Annual report 2010 external quality assessment in therapeutic drug monitoring and drug of abuse in Korea. J Lab Med Qual Assur 2011;33:S115-30.

4. Kim JH, Kim BK, Kim KW, Lee SY, Kwon GC, Chun S, et al. Annual report 2011 external quality assessment in therapeutic drug monitoring and drug of abuse in Korea. J Lab Med Qual Assur 2012;34:S129-47.
치료적약물농도검사 및 남용약물검사 신빙도조사 결과보고 (2013)

\section{정태동 • 구금경 ${ }^{1}$ - 전사일 ${ }^{1}$ 김정호 ${ }^{2}$ - 대한임상검사정도관리협회 약물검사분 과위원회 \\ ${ }^{1}$ 울산대학교 의과대학 서울아산병원 진단검사의학과, ${ }^{2}$ 연세대학교 의과대학 세브란스병원 진단검사의학과}

대한임상검사정도관리협회 약물검사분과에서는 2013년 총 2회에 걸쳐 치료적약물농도검사 및 남용 약물검사의 신빙도조사사업을 시행하였다. 1 회차 및 2 회차 모두 두 가지 농도의 치료적약물농도검 사 정도관리물질 그리고 양성 및 음성의 남용약물검사 정도관리물질을 대상기관에 발송하여 평가하 였다. 치료약물농도검사 신빙도조사에 참여한 기관은 1차 106기관이었다. 기관당 약물농도 검사종 목 수는 평균 5.6종목이었다. 가장 많은 기관에서 회신한 약물농도 검사종목은 valproic acid로 그 다 음은 digoxin, phenytoin, carbamazepine, tacrolimus (FK506) 순이었다. 저농도와 고농도 정도 관리물질의 검사실 간 변이 계수는 각각 $9.3 \%, 6.7 \%$ 였다. 검사장비는 Architect i System (Abbott Diagnostics, USA)을 가장 많이 사용하였고, Cobas Integra (Roche Diagnostics, Switzerland), Cobas c501 (Roche Diagnostics) 순이었다. 남용약물검사 신빙도조사 참여기관은 2012년보다 약 $30 \%$ 증가하였고, 정답률은 1회차 때에는 $100.0 \%$ 였고, 2회차 때에는 $98.2 \%$ 였다. 2013년도 약물 검사분과위원회 신빙도조사사업결과 치료적약물농도검사의 정밀도가 향상되었다. 약물검사를 실시 하는 각 검사실에서는 지속적인 신빙도조사사업 참여를 통해 검사의 질을 높여나가야 할 것으로 생각 되었다.

(J Lab Med Qual Assur 2014;36:12-22)

교신저자: 전사일

우)138-736 서울시 송파구 올림픽로 43길 88, 울산대학교 의과대학 서울아산병원 진단검사의학과

Tel: 02)3010-4513 Fax: 02)478-0884 E-mail: sailchun@amc.seoul.kr

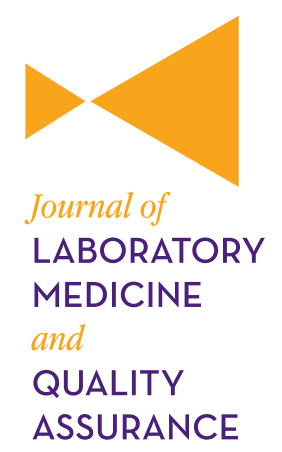

ASSURANCE 